\title{
Common risk factors and edentulism in adults, aged 50 years and over, in China, Ghana, India and South Africa: results from the WHO Study on global AGEing and adult health (SAGE)
}

Alexander Kailembo ${ }^{1 *}$, Raman Preet $^{2}$ and Jennifer Stewart Williams ${ }^{2,3}$

\begin{abstract}
Background: Edentulism (loss of all teeth) is a final marker of disease burden for oral health common among older adults and poorer populations. Yet most evidence is from high-income countries. Oral health has many of the same social and behavioural risk factors as other non-communicable diseases (NCDs) which are increasing rapidly in lowand middle-income countries with ageing populations. The "common risk factor approach" (CRFA) for oral health addresses risk factors shared with NCDs within the broader social and economic environment.

Methods: The aim is to improve understanding of edentulism prevalence, and association between common risk factors and edentulism in adults aged 50 years and above using nationally representative samples from China $(N=11,692)$, Ghana $(N=4093)$, India $(N=6409)$ and South Africa $(N=2985)$. The data source is the World Health Organization (WHO) Study on global AGEing and adult health (SAGE) Wave 1 (2007-2010). Multivariable logistic regression describes association between edentulism and common risk factors reported in the literature.

Results: Prevalence of edentulism: in China $8.9 \%$, Ghana $2.9 \%$, India $15.3 \%$, and South Africa $8.7 \%$. Multivariable analysis: in China, rural residents were more likely to be edentulous (OR 1.36; $95 \% \mathrm{Cl}$ 1.09-1.69) but less likely to be edentulous in Ghana (OR 0.53; $95 \% \mathrm{Cl} 0.31-0.91$ ) and South Africa (OR 0.52; $95 \% \mathrm{Cl} 0.30-0.90$ ). Respondents with university education (OR $0.31 ; 95 \% \mathrm{Cl} 0.18-0.53$ ) and in the highest wealth quintile (OR $0.68 ; 95 \% \mathrm{Cl} 0.52-0.90)$ in China were less likely to be edentulous. In South Africa respondents with secondary education were more likely to be edentulous (OR 2.82; $95 \% \mathrm{Cl} 1.52-5.21$ ) as were those in the highest wealth quintile (OR 2.78; $95 \% \mathrm{Cl} 1.16-6.70$ ). Edentulism was associated with former smokers in China (OR 1.57; $95 \% \mathrm{Cl}$ 1.10-2.25) non-drinkers in India (OR 1.65; $95 \%$ Cl 1.11-2.46), angina in Ghana (OR 2.86; $95 \%$ Cl 1.19-6.84) and hypertension in South Africa (OR 2.75; $95 \% \mathrm{Cl}$ 1.72-4.38). Edentulism was less likely in respondents with adequate nutrition in China (OR 0.68; $95 \%$ Cl 0.53-0.87). Adjusting for all other factors, compared with China, respondents in India were $50 \%$ more likely to be edentulous.
\end{abstract}

Conclusions: Strengthening the CRFA should include addressing common determinants of health to reduce health inequalities and improve both oral and overall health.

Keywords: Oral health, Tooth loss, Periodontal, Caries, Common risk factor approach, CRFA, Noncommunicable diseases, NCDs, Low- and middle-income countries, LMICs

\footnotetext{
* Correspondence: alexkailembo@gmail.com

${ }^{1}$ Elite Dental Clinic, 6th Floor, Oasis Office Complex, Plot No. 14/15, Haile

Selassie Road, P.O Box 38394, Masaki, Dar es salaam, Tanzania

Full list of author information is available at the end of the article
} 


\section{Background}

Oral health is fundamental for general health, functioning and well-being. The Global Burden of Disease 2010 Study estimated that oral conditions (untreated caries, severe periodontitis and severe tooth loss) accounted for almost $2 \%$ of all years lived with disability. Disability adjusted life-years (DALYs) due to oral conditions increased by 20.8 \% between 1990 and 2010, largely due to population growth and ageing [1-3]. This epidemiological study describes patterns of edentulism (loss of all teeth) in four low- and middle-income countries (LMICs) in Asia and Africa. Although DALYs for edentulism have fallen world-wide, the profile of edentulism is not homogeneous between or within countries and evidence of oral health in LMICs is limited [4].

Scientific and technological developments in oral health treatments and improved hygiene have helped prevent and control diseases of the mouth, yet advances in oral health science have largely benefited more advantaged populations in high-income countries (HICs). Research aimed at improving oral health should take into account social as well as biological determinants. People are now living longer in all parts of the world and the impact of poor oral health on the quality of life of older adults is an important public health issue [5]. In particular, efforts need to be strengthened in LMICs [3, 6-8] where periodontal diseases and caries are often "solved" by tooth/teeth extraction instead of conservation [9-12].

Observational evidence points to tobacco smoking $[13,14]$, alcohol consumption $[15,16]$ and poor nutrition $[9,17]$ as behavioural risk factors for edentulism. Studies also show that socio-demographic characteristics such as increasing age, gender, rural geo-locality, less education, and lower socioeconomic status [18-24] are also predictors of edentulism. In addition, both clinical and epidemiological associations have been observed between periodontal diseases and other chronic non-communicable diseases (NCDs) such as type 2 diabetes [25], angina pectoris [26], hypertension [27] and respiratory [28] and cardiovascular diseases [6, 29]. However all of these relationships vary according to the characteristics of the populations being studied [29].

In 2015, the proportion of people in the world aged 65 and above was $8.5 \%$ of the total 7.3 billion people worldwide. This segment of the global population is expected to increase by more than $60 \%$, from 617.1 million to about one billion, between 2015 and 2030 equivalent to about $12 \%$ of the world's population. The proportion of older people will continue to grow in the following 20 years. By 2050 people in the world aged 65 and above will comprise about $16.7 \%$ of the estimated total population of 9.4 billion people. Therefore the average annual increase in the sheer numbers of people aged
65 and above between 2015 and 2050 will be 27.1 million [30].

Although the proportion of people aged 65 and above within the Asian region was $7.9 \%$ in 2015 this translates to 341.1 million people or $5.3 \%$ of the people in the world aged 65 and above. By 2050, about 975.3 million, or two thirds of the world's population of people aged 65 and above will live in the Asian region. These figures are dominated by China and India, both of which have current populations exceeding one billion. In contrast, the African region has a relatively young age structure with about $3.5 \%$ of the population aged 65 years and above in 2015. Yet the Region is facing major demographic shifts. It is estimated that by 2050 this proportion of older adults in the Region will double to $6.7 \%$ being an almost fourfold increase from 40.6 million to 150.5 million adults aged 65 years and above between 2015 and 2050 [30, 31].

As the sheer numbers of older adults increases over the next decade, so will the burden of chronic periodontal and other NCDs, with a disproportionately higher share expected in LMICs [32]. Over the next 20 years the overall burden of NCDs is predicted to increase from 60 to $79 \%$ in Asia and from 28 to $51 \%$ in Africa [33].

Oral health has many of the same social and behavioural risk factors as other NCDs and oral health promotion is being given increasing attention in developed countries [34]. The "common risk factor approach" (CRFA) addresses risk factors shared with NCDs within the broader social and economic environment. Tobacco use, for example, is linked to periodontal disease, tooth loss, and $90 \%$ of all lung cancers. Unhealthy diets are associated with coronary heart disease, type 2 diabetes, strokes, many cancers and dental caries. The CRFA offers an efficacious method of health promotion and illness prevention, which highlights the importance of the mouth-body connection for overall health and wellbeing [35].

The CRFA aims to address the broader social and economic determinants (of health) which, in turn, can help reduce unfair health inequalities and inequities in health [36, 37]. Some argue that failure to reduce inequalities in health in many HICs has been because strategies have focused too much on lifestyle change at the expense of not directing efforts and resources towards the broader social determinants of health $[36,38]$. Inequalities in oral health reflect the same socioeconomic gradient that occurs in all populations whereby the poor and disadvantaged have the worst health [36, 37, 39, 40].

Edentulism is a "final marker of disease burden for oral health" $[12,41]$ and an important indicator of dental caries [42-44]. If governments in developing countries are to adopt the CRFA to address oral health they need 
reliable standardised nationally representative epidemiological data and processes by which to convert evidence into information for policy and planning [7]. However evidence on oral health from developing countries is not consistent.

The oral health needs of older people in the African continent [45] are significant with edentulism prevalent in the poorest communities, among older adults and among the less educated [10]. Reports of edentulism prevalence in Asia are varied. In a study of communitydwelling adults aged 60 and above in India, almost one in six were completely edentulous and over $60 \%$ of dentate subjects had decayed teeth or root caries [46]. Yet a study of community-dwelling 65 to 74 year olds in China found that the prevalence of edentulism was only $4.5 \%$ and $3.5 \%$ in urban and rural residents respectively [47]. There is a clear need to ensure comparability between sampling and methods of data collection in epidemiological studies in developing countries where oral health is an emerging public health issue [48, 49].

A recent epidemiological study by Peltzer et al. [50] investigated factors associated with edentulism in a pooled six-country data set comprising China, Ghana, India, Mexico, Russia and South Africa. The authors identified older age, lower education, NCDs, tobacco use, and inadequate fruit and vegetable consumption as risk factors for edentulism. However, the pooled analysis masks important differences within and between countries. In this study, we use a similar nationally comparable standardised study sample of adults to specifically investigate common risk factors for edentulism at the country level. The aim is to improve understanding of edentulism prevalence and association between common risk factors and edentulism (self-reported) in adults, aged 50 years and above, in China, Ghana, India and South Africa.

\section{Methods \\ Data collection}

The data source for this study is the World Health Organization (WHO) Study on global AGEing and adult health (SAGE) Wave 1 (2007-2010) which aims to address the gap in reliable and scientific knowledge on ageing and adult health in LMICs. WHO-SAGE is a longitudinal study of nationally representative samples of adults aged 50 and above in China, Ghana, India, Mexico, Russia and South Africa. Smaller non-representative samples of adults aged 18 to 49 years were collected for comparative purposes. Data analysed here were collected from face-to-face interviews using structured household and individual questionnaires.

WHO-SAGE employed a stratified random sampling strategy in all countries, with households as the final sampling units. The strata ensure representation of a range of living conditions and urban and rural localities in each country. Household-level analysis weights and person-level analysis weights were calculated for each country with post-stratification weights to adjust for age and sex distributions and non-response [51]. When multiple countries are analysed as a single data set, age and sex standardisations based on WHO's World Standard Population [52] adjust for between-country age and sex differences. WHO-SAGE data sets, including sampling weights, are in the public domain. Further details of WHO-SAGE are given elsewhere [53].

\section{Study variables}

The binary dependent variable "edentulism" was derived from answers to the question in the individual questionnaire: "Have you lost all your natural teeth?" Those who responded "yes" were defined as edentulous, and those who responded "no" to this question were categorized as being "dentate".

The choice of independent variables, or "common risk factors" was informed by the literature [35, 36]. Sociodemographic variables are sex, age, residence, education and wealth status. Sex is male or female. The age categories are 50-59 years vs. $60-69$ years vs. $70-79$ years vs. $80+$ years. Residence (geo-locality) is urban or rural. Education refers to the highest reported achieved level of education and is grouped no schooling vs. primary vs. secondary vs. university or college. All of these independent variables were directly derived from the individual questionnaires.

Information on ownership of household assets was taken directly from household questionnaires and converted to a household wealth status variable. This was then linked to the individual questionnaires. The SAGE household questionnaire captures information on household characteristics (eg cooking oil, floor and roof types), ownership of durable goods (eg radio, car) and access to basic services (eg electricity, clean water and sanitation). In order to construct an asset-based index from this information it was necessary to develop weights to assign to household assets. Principal Components Analysis was used to generate weights from which raw continuous scores, indicative of household wealth, were derived. These scores were transformed into "wealth quintiles" with quintile one representing the lowest wealth and quintile five the highest $[54,55]$. The above steps were undertaken by WHO.

Health behaviours are smoking (non-smoker vs. daily smoker vs. non-daily smoker vs. former smoker) alcohol use (drinkers vs. non-drinkers) and nutritional status derived from answers to the questions; "How many servings of fruit do you eat on a typical day?" and "How many servings of vegetables do you eat on a typical day?" Respondents with five or more servings are "adequate" and those with less than five servings are "inadequate". 
Chronic conditions are diabetes, angina and hypertension. Binary variables denote yes or no answers to questions that asked whether the respondents had "ever been diagnosed" with the condition. A country dummy variable (with China as the reference group) is included in the pooled multivariable analysis to adjust for country differences.

\section{Study sample}

The available data set of WHO SAGE Wave 1 individual respondents from China, Ghana, India, Mexico, Russia and South Africa comprised 47,443 respondents. The data for Mexico $(n=5548)$ and Russia $(n=4947)$ were not included because of high percentages of missing data on the dependent variable (52 \% in Mexico and $13 \%$ in Russia).

The analysis in this study compares two sets of countries in two distinct geographic regions - China and India in Asia and Ghana and South Africa in SubSaharan Africa. Individuals who did not complete the SAGE individual questionnaire were not included China $(n=237)$, Ghana $(n=463)$, India $(n=968)$ and South Africa $(n=2)$. Respondents aged less than 50 years were also excluded from the study - China $(n=1636)$, Ghana $(n=805)$, India $(n=4670)$ and South Africa $(n=$ 385). The potential study sample comprised SAGE Wave 1 respondents in China $(n=13,177)$, Ghana $(n=4305)$, India $(n=6560)$ and South Africa $(n=3840)$ who completed the surveys and were aged 50 years and over $(N=27,882)$. The final country study samples are reported in the Results section.

\section{Statistical analysis}

Only records with complete data on all study variables were analysed. Individual country samples are described by socio-demographic factors, health behaviours and chronic conditions. The prevalence of edentulism is estimated with $95 \%$ confidence intervals (CIs) to allow statistical comparisons between countries. Chi-squared tests show differences in prevalence by socio-demographic characteristics, behaviours and chronic conditions.

Univariable logistic regressions describe associations between socio-demographic factors, health behaviours and chronic conditions and edentulism in each country, and in the pooled data set. The criterion for inclusion in the multivariable analyses was set at $p<0.05$ in the pooled analysis. In some cases, eg sex in Ghana, India and South Africa, associations were not significant in the univariate analyses, but the variables were retained because of evidence of association with edentulism in the literature. Associations are presented as odds ratios (ORs) and $95 \%$ CIs.

All analyses applied either country or pooled weights appropriate for making estimates representative of the populations. The analyses were carried out using STATA 13 software (StataCorp, 2013).

\section{Results}

The study sample of adults aged 50 years and over in the four countries pooled was 25,179 . The largest sample was China $(n=11,692)$, followed by India $(n=6409)$, Ghana $(n=4093)$ and South Africa $(n=2985)$. Proportions of females to males were just above $50 \%$ in China and South Africa and just under $50 \%$ in Ghana and India. Overall almost half the study sample was aged $50-59$ years, about $5 \%$ were aged $80+$ years, and $58 \%$ were rural residents (Table 1 ).

Table 2 gives the prevalence of edentulism by country and sample characteristics. Overall in the four countries, prevalence was $10.9 \%(N=2591)$. Prevalence was highest in India at (15.3\%; $95 \%$ CI 13.4-17.5) and lowest in Ghana (2.9 \%; 95 \% CI 2.3-3.6). Prevalence was significantly different between countries except for China (8.9 \%; $95 \%$ CI 8.1-9.8) and South Africa (8.7\%; $95 \%$ CI 7.0-10.8). In all four countries, the prevalence of edentulism was higher in females but the sex difference was significant $(p<0.001)$ only in China $(44.4 \%$ male vs. $55.6 \%$ female). The prevalence of edentulism was significantly different $(p<0.001)$ by age in China, Ghana and India. Edentulism was more prevalent in rural areas in China (57.9 \%) and in urban areas in Ghana (59.3 \%) and South Africa $(83.7 \%)$. These differences were significant in China $(p=0.005)$, Ghana $(p=0.020)$ and South Africa $(p<0.001)$. Differences in education gradients were observed in China $(p<0.001)$ and South Africa $(p=0.004)$. The wealth gradient was also significant in China and South Africa $(p<0.001$ for both). The country comparison for smoking status was significant for China $(p<0.001)$ and South Africa $(p=0.020)$ and for alcohol use the differences were significant for China $(p=0.001)$ and India $(p=0.001)$. There was a significant difference in nutritional status in China only $(p<0.001)$. The prevalence of diabetes was significantly different in Ghana $(p=0.012)$ and South Africa $(p=0.001)$, the prevalence of angina was significantly different in China $(p=0.001)$ and Ghana $(p=0.011)$, and the prevalence of hypertension was significantly different in China and South Africa $(p<0.001)$.

Table 3 reports the results of univariable logistic regressions of common risk factors associated with edentulism. Women had about $30 \%$ higher odds of being edentulous in China $(p<0.001)$. Age was significantly associated with edentulism in China and India whereby older aged respondents were more likely to be edentulous $(p<0.001)$. Rural residents in China were significantly ( $p=0.005)$ more likely to be edentulous, and urban residents in Ghana $(p=0.020)$ and South Africa $(p<0.001)$ were more likely to be edentulous. An education gradient 
Table 1 Weighted characteristics of the study population of adults aged 50+ years in China, Ghana, India and South Africa and pooled, SAGE Wave $1(N=25,179)$

\begin{tabular}{|c|c|c|c|c|c|c|c|c|c|c|}
\hline \multirow[t]{3}{*}{ Characteristics } & \multirow{2}{*}{\multicolumn{2}{|c|}{$\begin{array}{l}\text { China } \\
N=11,692\end{array}$}} & \multirow{2}{*}{\multicolumn{2}{|c|}{$\begin{array}{l}\text { Ghana } \\
N=4093\end{array}$}} & \multirow{2}{*}{\multicolumn{2}{|c|}{$\begin{array}{l}\text { India } \\
N=6409\end{array}$}} & \multirow{2}{*}{\multicolumn{2}{|c|}{$\begin{array}{l}\text { South Africa } \\
N=2985\end{array}$}} & \multirow{2}{*}{\multicolumn{2}{|c|}{$\begin{array}{l}\text { Pooled data } \\
N=25,179\end{array}$}} \\
\hline & & & & & & & & & & \\
\hline & $n$ & $(\%)$ & $n$ & $(\%)$ & $n$ & $(\%)$ & $n$ & $(\%)$ & $n$ & $(\%)$ \\
\hline \multicolumn{11}{|l|}{ Sex } \\
\hline Male & 5492 & 49.7 & 2127 & 52.0 & 3230 & 50.6 & 1189 & 49.8 & 12,038 & 49.6 \\
\hline Female & 6200 & 50.3 & 1966 & 48.0 & 3179 & 49.4 & 1796 & 50.2 & 13,141 & 50.4 \\
\hline \multicolumn{11}{|l|}{ Age group (years) } \\
\hline $50-59$ & 5067 & 44.9 & 1619 & 40.2 & 2862 & 47.9 & 1313 & 49.5 & 10,861 & 49.8 \\
\hline $60-69$ & 3555 & 32.3 & 1136 & 27.2 & 2182 & 31.2 & 965 & 30.9 & 7838 & 29.4 \\
\hline $70-79$ & 2464 & 18.6 & 931 & 22.9 & 1044 & 16.3 & 517 & 14.1 & 4956 & 15.9 \\
\hline $80+$ & 606 & 4.2 & 407 & 9.7 & 321 & 4.6 & 190 & 5.5 & 1524 & 4.9 \\
\hline \multicolumn{11}{|l|}{ Residence } \\
\hline Urban & 6030 & 49.2 & 1659 & 40.6 & 1654 & 29.0 & 2006 & 65.3 & 11,349 & 41.6 \\
\hline Rural & 5662 & 50.8 & 2434 & 59.4 & 4755 & 71.0 & 979 & 34.7 & 13,830 & 58.4 \\
\hline \multicolumn{11}{|l|}{ Highest education } \\
\hline No schooling & 2727 & 21.7 & 2257 & 53.9 & 3286 & 51.7 & 771 & 24.1 & 9041 & 31.2 \\
\hline Primary or less & 4384 & 40.0 & 855 & 21.4 & 1642 & 25.0 & 1444 & 46.6 & 8325 & 25.2 \\
\hline Secondary & 4014 & 33.6 & 837 & 21.0 & 1162 & 18.3 & 617 & 23.3 & 6630 & 29.0 \\
\hline University & 567 & 4.7 & 144 & 3.7 & 319 & 5.0 & 153 & 6.0 & 1183 & 4.6 \\
\hline \multicolumn{11}{|l|}{ Wealth quintile } \\
\hline 1 (Lowest) & 2259 & 15.7 & 812 & 18.2 & 1043 & 18.2 & 548 & 19.4 & 4662 & 16.5 \\
\hline 2 & 2284 & 17.8 & 802 & 19.0 & 1185 & 19.2 & 608 & 20.2 & 4879 & 18.3 \\
\hline 3 & 2337 & 20.3 & 828 & 20.9 & 1176 & 18.7 & 608 & 19.4 & 4949 & 19.6 \\
\hline 4 & 2429 & 23.6 & 843 & 20.9 & 1393 & 20.0 & 612 & 20.0 & 5277 & 22.4 \\
\hline 5 (Highest) & 2383 & 22.6 & 808 & 21.0 & 1612 & 23.9 & 609 & 21.0 & 5412 & 23.2 \\
\hline \multicolumn{11}{|l|}{ Smoking } \\
\hline Non-smoker & 7794 & 64.1 & 3037 & 75.2 & 3048 & 45.7 & 1934 & 66.9 & 15,813 & 58.5 \\
\hline Daily smoker & 2849 & 26.7 & 402 & 8.1 & 2826 & 46.5 & 664 & 20.1 & 6741 & 32.8 \\
\hline Non-daily smoker & 302 & 2.5 & 112 & 2.6 & 195 & 3.0 & 115 & 3.2 & 724 & 2.7 \\
\hline Former smoker & 747 & 6.7 & 542 & 14.1 & 340 & 4.8 & 272 & 9.8 & 1901 & 6.0 \\
\hline \multicolumn{11}{|l|}{ Alcohol use } \\
\hline Drinker & 3612 & 33.9 & 2389 & 57.8 & 1015 & 15.9 & 827 & 25.4 & 7843 & 28.3 \\
\hline Non-drinker & 8080 & 66.1 & 1704 & 42.2 & 5394 & 84.1 & 2158 & 74.6 & 17,336 & 71.7 \\
\hline \multicolumn{11}{|l|}{ Nutritional status } \\
\hline Inadequate & 1413 & 9.6 & 2840 & 68.0 & 5711 & 90.4 & 2186 & 68.4 & 12,150 & 35.9 \\
\hline Adequate & 10,279 & 90.4 & 1253 & 32.0 & 698 & 9.6 & 799 & 31.6 & 13,029 & 64.1 \\
\hline
\end{tabular}

Chronic conditions

Diabetes

$\begin{array}{ccccccccccc}\text { Yes } & 785 & 6.7 & 161 & 3.9 & 471 & 6.5 & 297 & 9.6 & 1714 & 6.3 \\ \text { No } & 10,907 & 93.3 & 3932 & 96.1 & 5938 & 93.5 & 2688 & 90.6 & 23,465 & 93.7 \\ \text { Angina } & & & & & & & & & & \\ \text { Yes } & 1059 & 8.0 & 138 & 3.7 & 320 & 5.5 & 176 & 4.9 & 1693 \\ \text { No } & 10,633 & 92.0 & 3955 & 96.3 & 6084 & 94.5 & 2809 & 95.1 & 23,486 & 93.2\end{array}$


Table 1 Weighted characteristics of the study population of adults aged 50+ years in China, Ghana, India and South Africa and pooled, SAGE Wave $1(N=25,179)$ (Continued)

\begin{tabular}{llllllllll}
\hline $\begin{array}{l}\text { Hypertension } \\
\text { Yes }\end{array}$ & 3254 & 26.8 & 548 & 14.0 & 1120 & 16.8 & 922 & 31.0 & 5844 \\
No & 8438 & 73.2 & 3545 & 86.0 & 5289 & 83.2 & 2063 & 69.0 & 19,335 \\
\hline
\end{tabular}

was evident in China wherby the more educated groups were significantly less likely to be edentulous $(p<0.001)$. The pattern was reversed in South Africa where respondents who had primary or secondary schooling were significantly more likely to be edentulous compared with those who had no schooling $(p<0.001)$. There were also country differences in the direction of association with smoking. Compared with non-smokers, the odds of former smokers being edentulous were about $60 \%$ higher in China $(p<0.001)$ and the odds of daily smokers being edentulous were about $80 \%$ higher in South Africa $(p=0.033)$. Compared with drinkers, the odds of nondrinkers being edentulous were $30 \%$ higher in China and $60 \%$ higher in India $(p<0.001$ both). In China respondents with adequate nutritional status were half as likely to be edentulous $(p<0.001)$, respondents with angina had $60 \%$ higher odds of being edentulous $(p=$ 0.001 ) and the odds of respondents with hypertension being edentulous were about $50 \%$ higher $(p<0.001)$. In Ghana respondents with angina were three times more likely to be edentulous $(p=0.016)$ and respondents with diabetes were over two and a half times more likely to be edentulous $(p=0.015)$. In South Africa the odds of respondents with diabetes being edentulous were 2.3 times higher $(p=0.002)$ and the odds of respondents with hypertension being edentulous were about 3.4 times higher $(p<0.001)$.

In multivariable logistic regression (Table 4) edentulousness was significantly associated with the oldest respondents (aged 80+) and females in Ghana (OR 1.56; $95 \%$ CI 1.01-2.42), holding all other variables constant. In China association between female sex and edentulism attenuated to non-significance due to confounding, yet age remained significant in the presence of sex and all other covariates. Rural residents in China were significantly more likely to be edentulous (OR 1.36; 95 \% CI 1.109-1.69) but rural residents were less likely to be edentulous in Ghana (OR 0.53; $95 \%$ CI 0.31-0.91) and South Africa (OR 0.52; 95 \% CI 0.30-0.90) when holding all other variables constant.

Compared with those with no schooling, respondents with higher education in China were significantly less likely to be edentulous and respondents in South Africa with primary or secondary education were significantly more likely to be edentulous, when all other variables were held constant.
In the multivariable regressions, compared with nonsmokers, former smokers in China were significantly more likely to be edentulous (OR 1.57; 95 \% CI 1.102.25), and daily smokers in South Africa were significantly more likely to be edentulous (OR 2.24; 95 \% CI 1.22-4.13). In the presence of all other variables, compared with drinkers, non-drinkers in India were significantly more likely to be edentulous (OR 1.65; 95 \% CI 1.11-2.46) and respondents with adequate nutrition in China were significantly less likely to be edentulous (OR 0.68 ; 95 \% CI 0.53-0.87). In the multivariable analysis in Ghana, respondents with angina were significantly more likely to be edentulous (OR 2.86; 95 \% CI 1.19-6.84), respondents with diabetes in Ghana were significantly more likely to be edentulous (OR 2.57; 95 \% CI 1.195.59), and respondents with hypertension in South Africa were significantly more likely to be edentulous (OR 2.75; 95 \% CI 1.72-4.38).

In the multivariable regression of the data set for all countries pooled, the likelihood of edentulism was higher amongst those who were older and had less education. Holding all other variables constant, compared with 50-59 year olds, respondents aged $80+$ years were seven times more likely to be edentulous (OR 7.67; $95 \%$ CI 5.93-9.91), and those with university education were $60 \%$ less likely to be edentulous compared with those with no education (OR 0.44; 95 \% CI 0.28-0.68). Compared with drinkers, non-drinkers were $30 \%$ more likely to be edentulous when all other variables were held constant (OR 1.32; 95 \% CI 1.08-1.60). Compared with the reference country China and holding all other variables constant, respondents in India were $50 \%$ more likely to be edentulous (OR 1.51; 95 \% CI 1.14-1.99) and respondents in Ghana were $80 \%$ less likely to be edentulous (OR 0.21; 95 \% CI 0.15-0.28).

\section{Discussion}

This study of self-reported edentulism in adults aged 50 and above in four LMICs has two sets of important findings. The first is in relation to differences in the prevalence of self-reported edentulism in the two major emerging economies in Asia - China and India, and in contrast, two rapidly developing countries in the African continent - Ghana and South Africa. The second main finding relates to the distinct country-level differences in common risk factors for edentulism. 
Table 2 Weighted prevalence of self-reported edentulism according to characteristics of study population of adults aged 50+ years in China, Ghana, India and South Africa and pooled, SAGE Wave 1

\begin{tabular}{|c|c|c|c|c|c|c|c|c|c|c|c|c|c|c|c|}
\hline \multirow[t]{2}{*}{ Characteristics } & \multicolumn{3}{|c|}{ China } & \multicolumn{3}{|c|}{ Ghana } & \multicolumn{3}{|c|}{ India } & \multicolumn{3}{|c|}{ South Africa } & \multicolumn{3}{|c|}{ Pooled data } \\
\hline & $\bar{N}$ & $\%$ & $95 \% \mathrm{Cl}$ & $N$ & $\%$ & $95 \% \mathrm{Cl}$ & $N$ & $\%$ & $95 \% \mathrm{Cl}$ & $N$ & $\%$ & $95 \% \mathrm{Cl}$ & $N$ & $\%$ & $95 \% \mathrm{Cl}$ \\
\hline Prevalence & 1250 & 8.9 & $8.1-9.8$ & 112 & 2.9 & $2.3-3.6$ & 916 & 15.3 & $13.4-17.5$ & 313 & 8.7 & $7.0-10.8$ & 2591 & 10.9 & $9.9-11.9$ \\
\hline Sex & $n$ & $\%$ & $P$-value & $n$ & $\%$ & $P$-value & $n$ & $\%$ & $P$-value & $n$ & $\%$ & $P$-value & $n$ & $\%$ & $P$-value \\
\hline Male & 555 & 44.4 & $<0.001$ & 47 & 45.0 & 0.220 & 436 & 47.0 & 0.274 & 105 & 38.2 & 0.713 & 1143 & 44.7 & 0.004 \\
\hline Female & 695 & 55.6 & & 65 & 55.0 & & 480 & 53.0 & & 208 & 61.8 & & 1448 & 55.3 & \\
\hline \multicolumn{16}{|c|}{ Age group (years) } \\
\hline $50-59$ & 161 & 13.9 & $<0.001$ & 27 & 24.9 & $<0.001$ & 225 & 30.8 & $<0.001$ & 105 & 36.5 & 0.072 & 518 & 22.0 & $<0.001$ \\
\hline $60-69$ & 335 & 30.0 & & 24 & 20.5 & & 296 & 29.4 & & 104 & 34.2 & & 759 & 28.4 & \\
\hline $70-79$ & 526 & 39.2 & & 25 & 24.5 & & 278 & 31.1 & & 79 & 20.0 & & 908 & 34.2 & \\
\hline $80+$ & 228 & 16.9 & & 36 & 30.1 & & 117 & 8.7 & & 25 & 9.3 & & 406 & 15.4 & \\
\hline \multicolumn{16}{|l|}{ Residence } \\
\hline Urban & 540 & 42.1 & 0.005 & 58 & 59.3 & 0.020 & 245 & 35.4 & 0.074 & 277 & 83.7 & $<0.001$ & 1120 & 36.2 & 0.036 \\
\hline Rural & 710 & 57.9 & & 54 & 45.7 & & 671 & 64.6 & & 36 & 16.3 & & 1471 & 63.8 & \\
\hline \multicolumn{16}{|c|}{ Highest education } \\
\hline $\begin{array}{c}\text { No } \\
\text { schooling }\end{array}$ & 531 & 42.0 & $<0.001$ & 74 & 62.2 & 0.551 & 499 & 55.5 & 0.100 & 36 & 10.0 & 0.004 & 1140 & 49.4 & $<0.001$ \\
\hline $\begin{array}{l}\text { Primary or } \\
\text { less }\end{array}$ & 464 & 39.5 & & 17 & 17.9 & & 259 & 25.8 & & 176 & 51.5 & & 916 & 33.1 & \\
\hline Secondary & 224 & 16.8 & & 17 & 15.7 & & 127 & 14.9 & & 93 & 34.4 & & 461 & 15.2 & \\
\hline University & 31 & 1.7 & & 4 & 4.2 & & 31 & 3.8 & & 8 & 4.1 & & 74 & 2.4 & \\
\hline \multicolumn{16}{|l|}{ Wealth quintile } \\
\hline 1 (Lowest) & 386 & 26.6 & $<0.001$ & 24 & 17.8 & 0.861 & 136 & 18.8 & 0.854 & 28 & 8.5 & $<0.001$ & 574 & 23.7 & $<0.001$ \\
\hline 2 & 274 & 21.4 & & 21 & 16.8 & & 176 & 18.1 & & 48 & 14.8 & & 519 & 19.9 & \\
\hline 3 & 264 & 22.9 & & 24 & 24.7 & & 178 & 17.5 & & 74 & 16.5 & & 540 & 20.0 & \\
\hline 4 & 197 & 16.7 & & 20 & 17.8 & & 195 & 21.4 & & 75 & 21.4 & & 487 & 18.4 & \\
\hline 5 (Highest) & 129 & 12.4 & & 23 & 23.0 & & 231 & 24.2 & & 88 & 38.8 & & 471 & 18.0 & \\
\hline \multicolumn{16}{|l|}{ Smoking } \\
\hline $\begin{array}{l}\text { Non- } \\
\text { smoker }\end{array}$ & 842 & 64.6 & $<0.001$ & 85 & 72.6 & 0.300 & 429 & 48.1 & 0.150 & 187 & 57.6 & 0.020 & 1543 & 57.2 & 0.020 \\
\hline $\begin{array}{r}\text { Daily } \\
\text { smoker }\end{array}$ & 273 & 23.7 & & 9 & 6.7 & & 385 & 42.2 & & 94 & 29.6 & & 761 & 32.3 & \\
\hline $\begin{array}{l}\text { Non-daily } \\
\text { smoker }\end{array}$ & 22 & 1.5 & & 1 & 0.6 & & 31 & 3.5 & & 5 & 0.4 & & 59 & 2.4 & \\
\hline $\begin{array}{l}\text { Former } \\
\text { smoker }\end{array}$ & 113 & 10.2 & & 17 & 20.1 & & 71 & 6.2 & & 27 & 12.4 & & 228 & 8.1 & \\
\hline \multicolumn{16}{|l|}{ Alcohol use } \\
\hline Drinker & 329 & 28.8 & 0.001 & 58 & 53.3 & 0.317 & 116 & 11.0 & 0.001 & 79 & 22.9 & 0.576 & 582 & 20.4 & $<0.001$ \\
\hline Non-drinker & 921 & 71.2 & & 54 & 46.7 & & 800 & 89.0 & & 234 & 77.1 & & 2009 & 79.6 & \\
\hline \multicolumn{16}{|l|}{ Nutritional status } \\
\hline Inadequate & 253 & 16.7 & $<0.001$ & 75 & 66.9 & 0.816 & 798 & 89.4 & 0.500 & 235 & 74.2 & 0.207 & 1361 & 51.7 & $<0.001$ \\
\hline Adequate & 997 & 83.3 & & 37 & 33.1 & & 118 & 10.6 & & 78 & 25.8 & & 1230 & 48.3 & \\
\hline
\end{tabular}

Chronic conditions

Diabetes

\begin{tabular}{|c|c|c|c|c|c|c|c|c|c|c|c|c|c|c|c|}
\hline Yes & 101 & 7.8 & 0.210 & 8 & 9.0 & 0.012 & 77 & 8.4 & 0.135 & 68 & 18.0 & 0.001 & 254 & 7.7 & 0.067 \\
\hline No & 1149 & 92.2 & & 104 & 91.0 & & 839 & 91.6 & & 245 & 82.0 & & 2337 & 92.3 & \\
\hline
\end{tabular}


Table 2 Weighted prevalence of self-reported edentulism according to characteristics of study population of adults aged 50+ years in China, Ghana, India and South Africa and pooled, SAGE Wave 1 (Continued)

\begin{tabular}{|c|c|c|c|c|c|c|c|c|c|c|c|c|c|c|c|}
\hline \multicolumn{16}{|l|}{ Angina } \\
\hline Yes & 173 & 11.8 & 0.001 & 7 & 10.1 & 0.011 & 55 & 5.7 & 0.827 & 33 & 7.2 & 0.146 & 268 & 8.6 & 0.018 \\
\hline No & 1077 & 88.2 & & 105 & 89.9 & & 861 & 94.3 & & 280 & 92.8 & & 2323 & 91.4 & \\
\hline \multicolumn{16}{|c|}{ Hypertension } \\
\hline Yes & 465 & 34.5 & $<0.001$ & 10 & 11.8 & 0.603 & 175 & 16.3 & 0.777 & 173 & 57.7 & $<0.001$ & 823 & 25.5 & 0.026 \\
\hline No & 785 & 65.5 & & 102 & 88.2 & & 741 & 83.7 & & 140 & 42.3 & & 1768 & 74.5 & \\
\hline
\end{tabular}

The high prevalence of edentulism in India (15.3\%) is consistent with other findings. The World Health Organization [44] estimated the prevalence of edentulism among 65-74 year olds in India at $19 \%$ [44] and Peltzer et al. [50] reported edentulism prevalence in India at $16.3 \%$ (95\% CI 14.3-18.4). Of the 1240 elderly Indian subjects examined in their study, Sha and Sundaram showed that $15.2 \%$ were edentulous [46]. There has been a general trend in India to extract diseased teeth, especially among older adults and many take the view that teeth loss is a natural part of ageing [46].

Similar to the results of a previous study of oral health in SAGE countries [50] the prevalence in Ghana was only about $3 \%$, but three times higher in China and South Africa at 8-9 \%. In younger African adults (aged 35-44 years) edentulism prevalence has been estimated at $1 \%$ [7]. One reason for this is that many people in African countries live in rural communities where there is limited access to refined sugars, although this is changing with increasing urbanisation. However, urban to rural migration is occurring at different levels and rates in the African continent, which may also be a reason for the observed country differences in edentulism. In South Africa in 2010, only about $38 \%$ of the population lived in rural areas compared with $42 \%$ ten years earlier, while in Ghana about half the population lived in rural areas in 2010, compared with $58 \%$ in 2000 [56].

The $9 \%$ prevalence of edentulism in China in people aged 50 and over is consistent with the results of a national epidemiological survey conducted in China in 2005 in which edentulism prevalence was reported at $7 \%$ in the $65-74$ year age group and similar to a WHO estimate of $11 \%$ [44]. China is also facing rapid rural to urban migration which, as noted above, is impacting on oral health [57]. For example about $60 \%$ of the Chinese population lived in rural areas in 2000 compared with about $50 \%$ in 2010 [56].

Between country differences are shown in the results of the pooled multivariable regression. After adjusting for sex, age, residence, education wealth, smoking, alcohol, nutrition, and the self-reported chronic conditions angina, diabetes and hypertension, compared with the reference country, China, respondents in India were significantly $50 \%$ more likely to be edentulous and respondents in Ghana were significantly 80 \% less likely to be edentulous. These findings are broadly consistent with WHO 2000 estimates of edentulism prevalence in 65 to 74 year olds of $11 \%$ in China and $19 \%$ in India $[9,44]$.

The association between tooth loss and older age has been widely reported in studies conducted in many countries throughout the world [6, 20, 49,58-61]. In the univariable analyses, differences in edentulism prevalence were significant across the four age categories (50-59, 50-69, 70-79 and 80+) in China, Ghana and India, but not South Africa. However, in China and India only, the likelihood of edentulism was significantly higher in all age groups, compared with the reference group (50-59 years) after adjusting for sex, residence, education wealth, smoking, alcohol, nutrition, and the self-reported chronic conditions angina, diabetes and hypertension. In the two African countries, the association between older age and edentulism was significant only when comparing the 50-59 and 80+ year groups. When a regressor is categorised the placing of cut points can influence results [62]. In order to investigate the sensitivity of the association between age and edentulism, we re-analysed the data using three, instead of four, age categories - 50-59 years vs. 60-69 years vs. $70+$ years. The age groups $70-79$ and $80+$ years were collapsed because of relatively small cell sizes. As with the first analysis, there were positive age gradients in each of the countries, and in Ghana and South Africa the odds were significant only for the oldest $70+$ age group.

In the univariable analysis, women in China were $30 \%$ more likely to be edentulous but the association attenuated to non-significance after adjusting for age, residence, education wealth, smoking, alcohol, nutrition and the chronic conditions angina, diabetes and hypertension. In contrast, the association between sex and edentulism was not significant in Ghana in the univariable analysis, but in the multivariable analysis, women in Ghana were significantly $60 \%$ more likely to be edentulous. Compared with the univariable regression, the multivariable regression for Ghana showed a lower likelihood of edentulism for the 80+ age group, rural residents, and those with self-reported 
Table 3 Univariable logistic regression of common risk factors associated with edentulism, adults aged 50+ years in China, Ghana, India and South Africa and pooled, SAGE Wave 1 (weighted)

\begin{tabular}{|c|c|c|c|c|c|c|c|c|c|c|}
\hline \multirow[t]{2}{*}{ Characteristics } & \multicolumn{2}{|l|}{ China } & \multicolumn{2}{|l|}{ Ghana } & \multicolumn{2}{|l|}{ India } & \multicolumn{2}{|l|}{ South Africa } & \multicolumn{2}{|l|}{ Pooled data } \\
\hline & OR $(95 \% \mathrm{Cl})$ & $p$-value & OR $(95 \% \mathrm{Cl})$ & $p$-value & OR $(95 \% \mathrm{Cl})$ & $p$-value & OR $(95 \% \mathrm{Cl})$ & $p$-value & OR $(95 \% \mathrm{Cl})$ & $p$-value \\
\hline \multicolumn{11}{|l|}{ Sex } \\
\hline Male & 1 & & 1 & & 1 & & 1 & & 1 & \\
\hline Female & $1.27(1.14-1.40)$ & $<0.001$ & $1.33(0.84-2.12)$ & 0.221 & $1.19(0.87-1.63)$ & 0.274 & $1.09(0.70-1.68)$ & 0.713 & $1.25(1.07-1.45)$ & 0.004 \\
\hline \multicolumn{11}{|l|}{ Age group (years) } \\
\hline $50-59$ & 1 & & 1 & & 1 & & 1 & & 1 & \\
\hline $60-69$ & $3.19(2.52-4.04)$ & $<0.001$ & $1.22(0.64-2.32)$ & 0.537 & $1.55(1.24-1.95)$ & $<0.001$ & $1.55(0.91-2.65)$ & 0.105 & $2.32(1.98-2.71)$ & $<0.001$ \\
\hline $70-79$ & $8.16(6.14-10.85)$ & $<0.001$ & $1.75(0.85-3.61)$ & 0.128 & $3.80(2.81-5.13)$ & $<0.001$ & $2.05(1.23-3.41)$ & 0.006 & $6.02(4.95-7.33)$ & $<0.001$ \\
\hline $80+$ & $20.09(14.31-28.20)$ & $<0.001$ & 5.45(3.05-9.75) & 0.000 & $3.79(2.62-5.49)$ & $<0.001$ & $2.60(0.86-7.66)$ & 0.093 & $10.19(7.86-13.23)$ & $<0.001$ \\
\hline \multicolumn{11}{|l|}{ Residence } \\
\hline Urban & 1 & & 1 & & 1 & & 1 & & 1 & \\
\hline Rural & $1.36(1.10-1.69)$ & 0.005 & $0.57(0.35-0.91)$ & 0.020 & $0.71(0.48-1.04)$ & 0.075 & $0.34(0.19-0.59)$ & $<0.001$ & $1.30(1.02-1.65)$ & 0.036 \\
\hline \multicolumn{11}{|l|}{ Highest education } \\
\hline No schooling & 1 & & 1 & & 1 & & 1 & & 1 & \\
\hline Primary & $0.46(0.39-0.55)$ & $<0.001$ & $0.72(0.31-1.64)$ & 0.429 & $0.9(0.7-1.2)$ & 0.669 & $2.81(1.64-4.81)$ & $<0.001$ & $0.55(0.47-0.63)$ & $<0.001$ \\
\hline Secondary & $0.22(0.17-0.29)$ & $<0.001$ & $0.64(0.35-1.17)$ & 0.143 & $0.7(0.5-0.9)$ & 0.041 & $3.90(2.04-7.48)$ & $<0.001$ & $0.29(0.24-0.35)$ & $<0.001$ \\
\hline University & $0.15(0.09-0.27)$ & $<0.001$ & $1.00(0.30-3.32)$ & 0.996 & $0.7(0.4-1.1)$ & 0.115 & $1.64(0.48-5.56)$ & 0.426 & $0.29(0.20-0.44)$ & $<0.001$ \\
\hline \multicolumn{11}{|l|}{ Wealth quintile } \\
\hline 1 (lowest) & 1 & & 1 & & 1 & & 1 & & 1 & \\
\hline 2 & $0.67(0.53-0.85)$ & 0.001 & $0.90(0.44-1.83)$ & 0.762 & $0.95(0.74-1.23)$ & 0.549 & $1.72(0.66-4.46)$ & 0.263 & $0.73(0.60-0.88)$ & 0.001 \\
\hline 3 & $0.62(0.53-0.73)$ & $<0.001$ & $1.21(0.55-2.65)$ & 0.634 & $0.90(0.65-1.26)$ & 0.504 & $2.02(0.86-4.77)$ & 0.107 & $0.68(0.57-0.80)$ & $<0.001$ \\
\hline 4 & $0.38(0.30-0.48)$ & $<0.001$ & $0.86(0.43-1.75)$ & 0.680 & $1.05(0.72-1.51)$ & 0.810 & $2.61(1.15-5.92)$ & 0.022 & $0.53(0.42-0.67)$ & $<0.001$ \\
\hline 5 (highest) & $0.29(0.21-0.39)$ & $<0.001$ & $1.11(0.55-2.24)$ & 0.761 & $0.98(0.69-1.37)$ & 0.890 & $4.85(2.08-11.33)$ & $<0.001$ & $0.50(0.40-0.63)$ & $<0.001$ \\
\hline \multicolumn{11}{|l|}{ Smoking } \\
\hline Non-smoker & 1 & & 1 & & 1 & & 1 & & 1 & \\
\hline Daily smoker & $0.87(0.71-1.07)$ & 0.172 & $0.85(0.43-1.68)$ & 0.635 & $0.84(0.66-1.08)$ & 0.171 & $1.81(1.05-3.13)$ & 0.033 & $1.01(0.86-1.18)$ & 0.908 \\
\hline Non-daily smoker & $0.57(0.36-0.91)$ & 0.019 & $0.23(0.03-1.70)$ & 0.149 & $1.13(0.65-1.96)$ & 0.660 & $0.14(0.03-0.70)$ & 0.017 & $0.90(0.62-1.33)$ & 0.604 \\
\hline Former smoker & $1.59(1.24-2.04)$ & $<0.001$ & $1.50(0.68-3.30)$ & 0.314 & $1.30(0.86-1.94)$ & 0.209 & $1.53(0.79-2.96)$ & 0.207 & $1.45(1.20-1.78)$ & $<0.001$ \\
\hline \multicolumn{11}{|l|}{ Alcohol use } \\
\hline Drinker & 1 & & 1 & & 1 & & 1 & & 1 & \\
\hline Non-drinker & $1.30(1.12-1.50)$ & $<0.001$ & $1.21(0.83-1.75)$ & 0.318 & $1.64(1.22-2.20)$ & $<0.001$ & $1.16(0.68-2.00)$ & 0.577 & $1.61(1.40-1.85)$ & $<0.001$ \\
\hline
\end{tabular}


Table 3 Univariable logistic regression of common risk factors associated with edentulism, adults aged 50+ years in China, Ghana, India and South Africa and pooled, SAGE Wave 1 (weighted) (Continued)

\begin{tabular}{|c|c|c|c|c|c|c|c|c|c|c|}
\hline \multicolumn{11}{|l|}{ Nutritional status } \\
\hline Inadequate & 1 & & 1 & & 1 & & 1 & & 1 & \\
\hline Adequate & $0.49(0.39-0.62)$ & $<0.001$ & $1.06(0.66-1.69)$ & 0.816 & $1.15(0.77-1.70)$ & 0.499 & $0.73(0.45-1.19)$ & 0.208 & $0.48(0.40-0.58)$ & $<0.001$ \\
\hline \multicolumn{11}{|c|}{ Chronic Conditions } \\
\hline Angina & $1.60(1.22-2.12)$ & 0.001 & $3.13(1.24-7.93)$ & 0.016 & $1.06(0.65-1.72)$ & 0.827 & $1.58(0.85-2.94)$ & 0.149 & $1.3(31.05-1.70)$ & 0.019 \\
\hline Diabetes & $1.20(0.90-1.60)$ & 0.210 & $2.56(1.20-5.46)$ & 0.015 & $1.38(0.90-2.13)$ & 0.137 & $2.28(1.36-3.82)$ & 0.002 & $1.27(0.98-1.65)$ & 0.067 \\
\hline Hypertension & 1.49(1.27-1.76) & $<0.001$ & $0.82(0.38-1.75)$ & 0.604 & $0.96(0.71-1.29)$ & 0.777 & $3.43(2.18-5.41)$ & $<0.001$ & $1.19(1.02-1.38)$ & 0.026 \\
\hline
\end{tabular}


Table 4 Multivariable logistic regression of common risk factors associated with edentulism, adults aged 50+ years in China, Ghana, India and South Africa and pooled, SAGE Wave 1 (weighted)

\begin{tabular}{|c|c|c|c|c|c|c|c|c|c|c|}
\hline \multicolumn{3}{|l|}{ China } & \multicolumn{2}{|l|}{ Ghana } & \multicolumn{2}{|l|}{ India } & \multicolumn{2}{|l|}{ South Africa } & \multicolumn{2}{|l|}{ Pooled data } \\
\hline Variable & OR $(95 \%$ Cl) & $p$-value & OR $(95 \%$ Cl) & $p$-value & OR $(95 \%$ Cl) & $p$-value & OR $(95 \%$ Cl) & $p$-value & OR $(95 \%$ Cl) & $p$-value \\
\hline \multicolumn{11}{|l|}{ Sex } \\
\hline Male & 1 & & 1 & & 1 & & 1 & & 1 & \\
\hline Female & $1.09(0.86-1.37)$ & 0.477 & $1.56(1.01-2.42)$ & 0.044 & $1.01(0.67-1.52)$ & 0.959 & $1.07(0.66-1.74)$ & 0.789 & $0.96(0.77-1.20)$ & 0.716 \\
\hline \multicolumn{11}{|l|}{ Age group } \\
\hline $50-59$ & 1 & & 1 & & 1 & & 1 & & 1 & \\
\hline $60-69$ & $2.80(2.25-3.50)$ & $<0.001$ & $1.16(0.62-2.20)$ & 0.635 & $1.51(1.20-1.92)$ & 0.001 & $1.45(0.86-2.43)$ & 0.162 & $2.03(1.74-2.36)$ & $<0.001$ \\
\hline $70-79$ & $6.74(5.22-8.70)$ & $<0.001$ & $1.73(0.83-3.59)$ & 0.140 & $3.80(2.84-5.09)$ & $<0.001$ & $1.70(0.98-2.96)$ & 0.059 & $4.94(4.10-5.96)$ & $<0.001$ \\
\hline $80+$ & 14.89 (10.88-20.37) & $<0.001$ & $5.25(2.80-9.83)$ & $<0.001$ & $3.59(2.50-5.16)$ & $<0.001$ & $2.89(1.29-6.45)$ & 0.010 & 7.67 (5.93-9.91) & $<0.001$ \\
\hline \multicolumn{11}{|l|}{ Residence } \\
\hline Urban & 1 & & 1 & & 1 & & 1 & & 1 & \\
\hline Rural & $1.36(1.09-1.69)$ & 0.007 & $0.53(0.31-0.91)$ & 0.022 & $0.70(0.45-1.08)$ & 0.110 & $0.52(0.30-0.90)$ & 0.021 & $1.01(0.77-1.32)$ & 0.964 \\
\hline \multicolumn{11}{|l|}{ Education } \\
\hline No schooling & 1 & & 1 & & 1 & & 1 & & 1 & \\
\hline Primary & $0.82(0.67-1.00)$ & 0.048 & $1.05(0.44-2.53)$ & 0.915 & $0.94(0.72-1.22)$ & 0.637 & $2.32(1.31-4.12)$ & 0.004 & $0.88(0.75-1.03)$ & 0.105 \\
\hline Secondary & $0.57(0.44-0.75)$ & $<0.001$ & $0.98(0.51-1.90)$ & 0.960 & $0.76(0.56-1.03)$ & 0.081 & $2.82(1.52-5.21)$ & 0.001 & $0.58(0.48-0.71)$ & $<0.001$ \\
\hline University & $0.31(0.18-0.53)$ & $<0.001$ & $1.31(0.38-4.54)$ & 0.665 & $0.60(0.33-1.12)$ & 0.107 & $1.29(0.36-4.58)$ & 0.693 & $0.44(0.28-0.68)$ & $<0.001$ \\
\hline \multicolumn{11}{|l|}{ Wealth quintile } \\
\hline 1 (lowest) & 1 & & 1 & & 1 & & 1 & & 1 & \\
\hline 2 & $0.89(0.71-1.12)$ & 0.317 & $0.87(0.41-1.84)$ & 0.714 & $0.91(0.65-1.28)$ & 0.586 & $1.68(0.68-4.10)$ & 0.258 & $0.85(0.70-1.03)$ & 0.100 \\
\hline 3 & $1.03(0.84-1.27)$ & 0.752 & $1.17(0.56-2.45)$ & 0.675 & $0.93(0.66-1.29)$ & 0.651 & $1.47(0.61-3.57)$ & 0.389 & $0.94(0.78-1.13)$ & 0.497 \\
\hline 4 & $0.76(0.60-0.94)$ & 0.015 & $0.80(0.37-1.70)$ & 0.553 & $1.08(0.74-1.57)$ & 0.703 & $1.61(0.71-3.67)$ & 0.256 & $0.83(0.67-1.03)$ & 0.094 \\
\hline 5 (highest) & $0.68(0.52-0.90)$ & 0.007 & $0.94(0.41-2.16)$ & 0.890 & $0.99(0.69-1.44)$ & 0.974 & $2.78(1.16-6.70)$ & 0.022 & $0.82(0.65-1.02)$ & 0.076 \\
\hline \multicolumn{11}{|l|}{ Smoking } \\
\hline Non-smoker & 1 & & 1 & & 1 & & 1 & & 1 & \\
\hline Daily smoker & $1.18(0.89-1.57)$ & 0.237 & $1.11(0.53-2.35)$ & 0.778 & $0.95(0.75-1.21)$ & 0.674 & $2.24(1.22-4.13)$ & 0.010 & $0.97(0.80-1.16)$ & 0.714 \\
\hline Nondaily smoke & $0.64(0.38-1.07)$ & 0.086 & $0.38(0.05-2.81)$ & 0.340 & $1.24(0.74-2.08)$ & 0.413 & $0.22(0.04-1.15)$ & 0.073 & $0.91(0.62-1.34)$ & 0.636 \\
\hline Former smoker & $1.57(1.10-2.25)$ & 0.015 & $1.86(0.79-4.40)$ & 0.157 & $1.29(0.83-1.99)$ & 0.260 & $1.81(0.86-3.79)$ & 0.118 & $1.36(1.05-1.77)$ & 0.020 \\
\hline \multicolumn{11}{|l|}{ Alcohol use } \\
\hline Drinker & 1 & & 1 & & 1 & & 1 & & 1 & \\
\hline Non-drinker & $1.17(0.98-1.40)$ & 0.088 & $1.09(0.70-1.69)$ & 0.701 & $1.65(1.11-2.46)$ & 0.014 & $1.24(0.57-2.70)$ & 0.595 & $1.32(1.08-1.60)$ & 0.006 \\
\hline
\end{tabular}


Table 4 Multivariable logistic regression of common risk factors associated with edentulism, adults aged 50+ years in China, Ghana, India and South Africa and pooled, SAGE Wave 1 (weighted) (Continued)

\begin{tabular}{|c|c|c|c|c|c|c|c|c|c|c|}
\hline \multicolumn{11}{|l|}{ Nutrition } \\
\hline Inadequate & 1 & & 1 & & 1 & & 1 & & 1 & \\
\hline Adequate & $0.68(0.53-0.87)$ & 0.003 & $1.05(0.65-1.69)$ & 0.846 & $1.31(0.83-2.08)$ & 0.243 & $0.68(0.42-1.10)$ & 0.114 & $0.82(0.63-1.05)$ & 0.113 \\
\hline \multicolumn{11}{|c|}{ Chronic conditions } \\
\hline Angina & $1.12(0.80-1.57)$ & 0.498 & $2.86(1.19-6.84)$ & 0.019 & $0.89(0.50-1.59)$ & 0.705 & $1.23(0.67-2.26)$ & 0.495 & $1.07(0.81-1.42)$ & 0.629 \\
\hline Diabetes & $0.93(0.69-1.27)$ & 0.659 & $2.57(1.19-5.59)$ & 0.017 & $1.46(0.92-2.31)$ & 0.111 & $1.24(0.69-2.24)$ & 0.472 & $1.24(0.93-1.65)$ & 0.143 \\
\hline Hypertension & $1.22(0.98-1.52)$ & 0.074 & $0.57(0.24-1.31)$ & 0.184 & $0.79(0.57-1.09)$ & 0.145 & $2.75(1.72-4.38)$ & $<0.001$ & $1.10(0.92-1.31)$ & 0.305 \\
\hline \multicolumn{11}{|l|}{ Country } \\
\hline China & & & & & & & & & 1 & \\
\hline Ghana & & & & & & & & & $0.21(0.15-0.28)$ & $<0.001$ \\
\hline India & & & & & & & & & $1.51(1.14-1.99)$ & 0.004 \\
\hline South Africa & & & & & & & & & $0.86(0.62-1.18)$ & 0.349 \\
\hline
\end{tabular}


angina and diabetes, suggesting that these factors confounded association between sex and edentulism in the univariable model.

However, evidence of associations between sex and edentulism in older adults is mixed. Observational evidence that females are more likely to be edentulous $[21,63,64]$ has been attributed to both biological and social factors. Studies have shown association between osteoporosis and oestrogen deficiency and periodontal diseases and tooth loss [65-67]. In some societies women, particularly those in higher socioeconomic groups, may be more concerned about their dental and facial appearance than men and therefore e more likely to opt for dentures when available [24, 64]. Other research shows that men tend to be more edentulous than women [68] or that the sex differences are not significant $[10,69]$ although this varies according to the populations studied [6]. It is important to note that differences in oral health are a function of both biological sex and gender with the later referring to behaviours resulting from the societal and cultural construction of male/female roles [23].

In China respondents in rural areas were significantly $40 \%$ more likely to be edentulous while rural respondents in Ghana and South Africa were significantly $50 \%$ less likely to be edentulous after adjusting for sex, age, education wealth, smoking, alcohol, nutrition, and the self-reported chronic conditions angina, diabetes and hypertension. Comparisons between urban and rural residents are complicated by the availability of and access to oral health treatment $[6,18]$. In the African continent these issues are complicated by a limited oral health workforce and poor working conditions as well as logistic problems in reaching people in rural communities [7]. Dental treatments and extractions are less likely to be available in poorer rural communities. However, factors such as family and social support and informal networks can also play a role in promoting oral health care [70].

Respondents with higher levels of completed education were significantly less likely to be edentulous in China, after adjusting for sex, age, residence, wealth, smoking, alcohol, nutrition, and the self-reported chronic conditions angina, diabetes and hypertension. In the multivariable models, education to primary or secondary levels compared with no schooling, was significantly associated with edentulism in South Africa but the edentulism/education association was not significant for Ghana or India. A number of studies show that higher education is protective of edentulism in older adults $[10,20,21]$. This can be explained by the role played by education in promoting the utilization of oral health services where available.

After adjusting for sex, age, residence, education, smoking, alcohol, nutrition, and the self-reported chronic conditions angina, diabetes and hypertension, the likelihood of edentulism in the highest compared with the lowest wealth quintile was significant and $30 \%$ less in China, and significantly almost three times higher in South Africa. Many studies in the literature report that oral health, like general health, is associated with lower socioeconomic status and wealth. However there apparent contradictory results may be due to a perception, which has been documented in African countries, that loss of teeth is an inevitable consequence of ageing. Elders are held in high regard in many traditional cultures in African countries, although this is gradually changing with increasing economic and social change [7, 45]. Another factor is that teeth extraction is seen in African cultures as being a socially acceptable solution for dental problems [10].

The patterns in the health behaviours smoking, alcohol use and nutrition are variable, possibly due to inconsistencies in self-reported responses. Adjusting for sex, age, residence, education, wealth, alcohol, nutrition, and the self-reported chronic conditions angina, diabetes and hypertension, former smokers in China were significantly $60 \%$ more likely to be edentulous compared with non-smokers and in South Africa, daily smokers were significantly $20 \%$ more likely to be edentulous than nonsmokers. Smoking is widely cited as a risk factor for poor oral health including tooth loss $[13,71,72]$. The findings that non-drinkers in India were significantly $60 \%$ more likely to be edentulous in the fully adjusted model is somewhat surprising given evidence of association between alcohol use and poor oral health [16, 72, 73]. However this is partly explained by the high proportion of non-drinkers $(84 \%)$ in the India study sample. In the fully adjusted models, respondents with an adequate intake of fruits and vegetables were significantly $30 \%$ less likely to be edentulous in China, while in the other three countries the association between nutrition and edentulism was not significant. Diets rich in saturated fats and refined sugars and low in fibres and vitamins have been associated with NCDs including dental caries in a number of countries $[17,74,75]$. The result for China may reflect the traditional Chinese diet being high in fruits and vegetables, although this is now changing with increased economic development [44].

In the fully adjusted model, in Ghana, respondents with angina were significantly three times more likely to be edentulous and respondents with diabetes were significantly $50 \%$ less likely to be edentulous. In South Africa respondents with hypertension were significantly almost three times more likely to be edentulous in the presence of sex, age, residence, education, wealth, smoking, alcohol, nutrition, angina and diabetes. There is evidence to support biological 
links between NCDs and oral health. Oral bacterial infections that normally precede tooth loss can influence systemic inflammatory and homeostatic factors such as $\mathrm{C}$ - reactive protein and leucocytes leading to vascular damage and atherosclerosis [76] and it has been suggested that having fewer teeth may affect healthier nutrient intake leading to increased risk of vascular diseases [77].

\section{Limitations}

It was not possible to establish causation because of the analyses were cross-sectional. Although the data collection was tightly controlled, it is possible that some respondents did not answer "honestly", particularly in relation to questions about smoking and alcohol. We also acknowledge the possibility of selection bias with different life expectancies in these four countries.

\section{Strengths}

The WHO-SAGE data are collected in a highly consistent manner. To our knowledge, this is the first study of its kind to use standardised data and definitions to specifically investigate common risk factor patterns of edentulousness in these four LMICs. The analysis conducted separately for each country provides insights not possible with only a pooled multi-country analysis. The results provide a platform for further work to help build an evidence-base to inform the development of contextspecific policies on oral health in LMICs.

\section{Conclusions}

The study calls for strengthening of the CRFA for oral and other NCDs [78]. The focus should be on the common determinants of health, community participation, partnerships with other sectors, healthy public policies and reducing health inequalities and inequities to achieve improvements in oral and overall health.

\begin{abstract}
Abbreviations
$\mathrm{Cl}$, confidence interval; CRFA, common risk factor approach; DALYs, Disability adjusted life years; HICs, high-income countries; LMICs, low-and middleincome countries; NCDs, non-communicable diseases; OR, odds ratio; SAGE, Study on global AGEing and adult health; WHO, World Health Organization
\end{abstract}

\section{Acknowledgements}

We are grateful to the respondents of WHO- SAGE Wave 1 in China, India, Ghana and South Africa and to the WHO for making the WHO-SAGE dataset publically available. Support for WHO- SAGE-Wave 1 was provided by the United States

National Institute on Aging (NIA) Division of Behavioral and Social Research (BSR) through Interagency Agreements (YA1323-08-CN-0020; Y1-AG-1005-01). We are also grateful to the feedback received from our reviewers.

\section{Funding}

AK is a Swedish Institute (SI) Scholarship Holder for the Master of Public Health program at Umeå University. RP received no funding for this work. JSW was supported by the FORTE grant for the Umeå Centre for Global Health Research (No. 2006-1512). The funders had no role in study design, data collection, analysis, decision to publish, or preparation of the manuscript.

\section{Availability of data and materials}

SAGE is committed to the public release of study instruments, protocols and meta- and micro-data: access is provided upon completion of the Users Agreement available through WHO's SAGE website (www.who.int/healthinfo/ systems/sage) and WHO's archive using the National Data Archive application (http://apps.who.int/healthinfo/systems/surveydata).

\begin{abstract}
Authors' contributions
AK made a substantial contribution to the conception of the study, analyzed data and wrote the first draft. RP participated in the conception of the manuscript and provided critical inputs to the Introduction and the Discussion. JSW directed the study, developed the first and last drafts, checked the analyses, drafted the response to peer review, provided critical inputs and advised at all stages of the manuscript. All authors approved the final draft.
\end{abstract}

\section{Competing interests}

The authors declare that they have no competing interests.

\section{Consent for publication}

Not applicable.

\section{Ethics approval and consent to participate}

The SAGE study was approved by the Ethics Review Committee, World Health Organization, Geneva, Switzerland and the individual ethics committees in each of the SAGE countries. Written informed consent was freely obtained from each individual participant. Confidential records of participants' consent are maintained by SAGE country teams.

\section{Author details}

${ }^{1}$ Elite Dental Clinic, 6th Floor, Oasis Office Complex, Plot No. 14/15, Haile Selassie Road, P.O Box 38394, Masaki, Dar es salaam, Tanzania. ${ }^{2}$ Unit of Epidemiology and Global Health, Department of Public Health and Clinical Medicine, Faculty of Medicine, Umeå University, Umeå, Sweden. ${ }^{3}$ Research Centre for Generational Health and Ageing, Faculty of Health, University of Newcastle, Newcastle, Australia.

Received: 16 March 2016 Accepted: 15 July 2016

Published online: 27 July 2016

References

1. Murray CJL, Vos T, Lozano R, Naghavi M, Flaxman AD, Michaud C, Ezzati M, Shibuya K, Salomon J, Abdalla S, et al. Disability-adjusted life years (DALYs) for 291 diseases and injuries in 21 regions, 1990-2010: a systematic analysis for the Global Burden of Disease Study 2010. Lancet. 2012;380:2198-227.

2. Murray CJL, Frenk J, Piot P, Mundel T. GBD 2.0: a continuously updated global resource. The Lancet. 2013;3:9-11. http://dx.doi.org/10.1016/S01406736(13)60225-1.

3. Marcenes W, Kassebaum NJ, Bernabe E, Flaxman A, Naghavi M, Lopez A, Murray CJ. Global burden of oral conditions in 1990-2010: a systematic analysis. In: J Dent Res. 2013;92(7):592-97. doi:10.1177/0022034513490168

4. Slade GD, Akinkugbe AA, Sanders AE. Projections of U.S. Edentulism prevalence following 5 decades of decline. J Dent Res. 2014;93(10):959-65.

5. van der Putten G-J, de Baat C, De Visschere L, Schols J. Poor oral health, a potential new geriatric syndrome. Gerodontology. 2014;31 Suppl 1:17-24.

6. Petersen PE, Yamamoto T. Improving the oral health of older people: the approach of the WHO Global Oral Health Programme. In: Community Dent Oral Epidemiol. 2005;33:81-92.

7. Thorpe S. Oral Health Issues in the African Region: Current situation and future perspectives. J Dent Educ. 2006;70:8-15.

8. Baelum V, van Palenstein Helderman W, Hugoson A, Yee R, Fejerskov O. A global perspective on changes in the burden of caries and periodontitis: implications for dentistry. In: J Oral Rehabil. England:

2007;34:872-906. discussion 940. doi:10.1111/j.1365-2842.2007.01799.x

9. Petersen PE. The World Oral Health Report 2003: continuous improvement of oral health in the 21st century-the approach of the WHO Global Oral Health Programme. Community Dent Oral Epidemiol. 2003;31 Suppl 1:3-23.

10. Esan TA, Olusile AO, Akeredolu PA, Esan AO. Socio-demographic factors and edentulism: the Nigerian experience. In: BMC Oral Health, vol. 4. 2004. p. 3.

11. Petersen PE: Global policy for improvement of oral health in the 21st century-implications to oral health research of World Health Assembly 
2007, World Health Organization. In: Community Dent Oral Epidemiol. Volume 37. Denmark; 2009:1-8. http://www.who.int/oral_health/media/en/ orh_report03_en.

12. Emami E, Raphael Freitas de Souza R, Kabawat M, Feine JS. The Impact of Edentulism on Oral and General Health. Int J Dent. 2013;2013: Article ID 498305:7. http://dx.doi.org/10.1155/2013/498305.

13. Arora M, Schwarz E, Sivaneswaran S, Banks E. Cigarette smoking and tooth loss in a cohort of older Australians: the 45 and up study. In: J Am Dent Assoc. Volume 141. United States; 2010: 1242-1249.

14. Northridge ME, Ue FV, Borrell LN, De La Cruz LD, Chakraborty B, Bodna S, Marshall S, Lamster IB. Tooth loss and dental caries in communitydwelling older adults in northern Manhattan. Gerodontology. 2012;29(2): e464-73.

15. Medina-Solis CE, Pontigo-Loyola AP, Perez-Campos E, Hernandez-Cruz P, Avila-Burgos L, Mendoza-Rodriguez M, Maupome G. Determinants of selfreported health @ Med Sci Monit. 2014;20:843-52. doi:10.12659/MSM.890100.

16. Kim HS, Son JH, Yi HY, Hong HK, Suh HJ, Bae KH. Association between harmful alcohol use and periodontal status according to gender and smoking. BMC Oral Health. 2014;14:73. doi:10.1186/1472-6831-14-73.

17. De Marchi RJ, Hugo FN, Padilha DM, Hilgert JB, Machado DB, Durgante PC, Antunes MT. Edentulism, use of dentures and consumption of fruit and vegetables in south Brazilian community-dwelling elderly. J Oral Rehabil. 2011;38(7):533-40.

18. Vargas CM, Yellowitz JA, Hayes KL. Oral health status of older rural adults in the United States. J Am Dent Assoc. 2003;134(4):479-86.

19. Pallegedara C, Ekanayake L. Tooth loss, the wearing of dentures and associated factors in Sri Lankan older individuals. Gerodontology. 2005:22:193-9

20. Dogan BG, Gokalp S. Tooth loss and edentulism in the Turkish elderly. In: Arch Gerontol Geriatr, vol. 54. Netherlands: A 2012 Elsevier Ireland Ltd; 2012. p. e162-6.

21. Gaio EJ, Haas AN, Carrard VC, Oppermann RV, Albandar J, Susin C. Oral health status in elders from South Brazil: a population-based study. Gerodontology. 2012;29(3):214-23.

22. Mendes DC, Poswar Fde O, de Oliveira MV, Haikal DS, da Silveira MF, Martins AM, De Paula AM. Analysis of socio-demographic and systemic health factors and the normative conditions of oral health care in a population of the Brazilian elderly. Gerodontology. 2012;29(2):e206-14.

23. Russell SL, Gordon S, Lukacs JR, Kaste LM. Sex/Gender differences in tooth loss and edentulism: historical perspectives, biological factors, and sociologic reasons. Dent Clin North Am. 2013;57(2):317-37.

24. Wennstrom A, Ahlqwist M, Stenman U, Bjorkelund C, Hakeberg M. Trends in tooth loss in relation to socio-economic status among Swedish women, aged 38 and 50 years: repeated cross-sectional surveys 1968-2004. BMC Oral Health. 2013;13:63

25. Kowall B, Holtfreter B, Volzke H, Schipf S, Mundt T, Rathmann W, Kocher T. Pre-diabetes and well-controlled diabetes are not associated with periodontal disease: the SHIP Trend Study. J Clin Periodontol. 2015;42:42230. doi: 10.1111/jcpe.12391.

26. Medina-Solis CE, Pontigo-Loyola AP, Perez-Campos E, Hernandez-Cruz P, Avila-Burgos L, Kowolik MJ, Maupome G. Association between edentulism and angina pectoris in Mexican adults aged 35 years and older: a multivariate analysis of a population-based survey. J Periodontol. 2014:85(3):406-16.

27. Ayo-Yusuf OA, Ayo-Yusuf IJ. Association of tooth loss with hypertension. S Afr Med J. 2008;98(5):381-5.

28. Scannapieco FA. Role of oral bacteria in respiratory infection. J Periodontol. 1999;70(7):793-802.

29. Mattila KJ, Asikainen S, Wolf J, Jousimies-Somer H, Valtonen V, Nieminen M. Age, dental infections, and coronary heart disease. J Dent Res. 2000;79(2):756-60

30. He W, Goodkind D, Kowal P. U.S. Census Bureau, International Population Reports, P95/16-1, An Aging World: 2015, U.S. Government Publishing Office, Washington, DC,2016.

31. World Health Organization. World Report on Ageing and Health. Geneva: WHO; 2015. p. 260

32. World Health Organization. The Global Burden of Disease 2004 update. Geneva: WHO; 2008. p. 146

33. Ng N, Kowal P, Kahn K, Naidoo N, Abdullah S, Bawah A, Binka F, Chuc N, Debpuur C, Egondi T, et al. Health inequalities among older men and women in Africa and Asia: evidence from eight Health and Demographic
Surveillance System sites in the INDEPTH WHO-SAGE study. Global Health Action. 2010;Suppl 2:96-107. doi:10.3402/gha.v3i0.5420.

34. McGrath C, Zhang W, Lo EC. A review of the effectiveness of oral health promotion activities among older people. Gerodontology. 2009;26:85-96.

35. Sheiham A, Watt RG. The common risk factor approach: a rational basis for promoting oral health. Community Dent Oral Epidemiol. 2000;28(6):399-406

36. Sheiham A, Alexander D, Cohen L, Marinho V, Moyses S, Petersen PE, Spencer J, Watt RG, Weyant R. Global oral health inequalities: task groupimplementation and delivery of oral health strategies. In: Adv Dent Res. 2011;23(2):259-67. doi:10.1177/0022034511402084.

37. Watt RG. Social determinants of oral health inequalities: implications for action. Community Dent Oral Epidemiol. 2012;40 Suppl 2:44-8.

38. Petersen PE. Challenges to improvement of oral health in the 21 st centurythe approach of the WHO Global Oral Health Programme. Int Dent J. 2004;54(6 Suppl 1):329-43.

39. Marmot M. Global action on social determinants of health. Bull World Health Organ. 2011;89:702

40. Hosseinpoor AR, Itani L, Peterson PE. Socio-economic Inequality in oral healthcare coverage : results from the World Health Survey. J Dent Res. 2012;91(3):275-81.

41. Cunha-Cruz J, Hujoel PP, Nadanovsky P. Secular trends in socio-economic disparities in edentulism: USA, 1972-2001. In: J Dent Res. 2007; 86(2):131-36.

42. Fure S, Zickert I. Incidence of tooth loss and dental caries in 60-, 70and 80-year-old Swedish individuals. Community Dent Oral Epidemiol. 1997;25(2):137-42.

43. Fure S. Ten-year Incidence of toothlLoss and dental caries in elderly Swedish individuals. Caries Res. 2003;37:462-9.

44. Joint WHO/FAO Expert Consultation on Diet, Nutrition and the Prevention of Chronic Diseases (2002 : Geneva, Switzerland) Diet, nutrition and the prevention of chronic diseases: report of a joint WHO/FAO expert consultation, Geneva, 28 January - 1 February 2002. (WHO technical report series; 916) 160 pages.

45. Ogunbodede EO. Population ageing and the implications for oral health in Africa. Gerodontology. 2013;30:1-2.

46. Shah N, Sundaram KR. Impact of socio-demographic variables, oral hygiene practices, oral habits and diet on dental caries experience of Indian elderly: a community-based study. Gerodontology. 2004:21:43-50.

47. Lin HC, Corbet EF, Lo ECM. Tooth Loss, Occluding Pairs, and Prosthetic Status of Chinese Adults. J Dent Res. 2001:80(5):1491-5.

48. Hobdell MH, Myburgh NG, Lalloo R, Chikte UM, Owen CP. Oral disease in Africa: a challenge to change oral health priorities. Oral Dis. 1997; 3(4):216-22.

49. Thompson WM. Epidemiology of oral health conditions in older people. Gerodontology. 2014;31 Suppl 1:9-16.

50. Peltzer K, Hewlett S, Yawson AE, Moynihan P, Preet R, Wu F, Guo G, Arokiasamy P, Snodgrass JJ, Chatterji S, et al. Prevalence of loss of all teeth (edentulism) and associated factors in older adults in China, Ghana, India, Mexico, Russia and South Africa. Int J Environ Res Public Health. 2014;11(11):11308-24.

51. Naidoo N. Working Paper Number 5. In: WHO, editor. WHO's Study on global AGEing and adult health (SAGE) Waves 0 and 1 sampling information for China, Ghana, India, Mexico, Russia and South Africa. Genève: WHO SAGE; 2012. p. 9

52. Ahmad OB, Boschi-Pinto C, Lopez AD, Murray CJL, Lozano R, Inoue M Age standardization of rates: a new WHO standard. In: GPE Discussion Paper Series: No31. Geneva: World Health Organization; 2001. p. 14.

53. Kowal P, Chatterji S, Naidoo N, Biritwum R, Fan W, Lopez Ridaura R, Maximova T, Arokiasamy P, Phaswana-Mafuya N, Williams S, et al. Data resource profile: the World Health Organization Study on global AGEing and adult health (SAGE). In: Int J Epidemiol. 2012;41:1639-1649. doi: 10. 1093/ije/dys210

54. Ferguson B, Murray CL, Tandon A, Gakidou E. Estimating permanent income using asset and indicator variables. In: Murray CL, Evans DB, editors. Health systems performance assessment debates, methods and empiricism. Geneva: World Health Organization; 2003.

55. Howe LD, Galobardes B, Matijasevich A, Gordon D, Johnston D, Onwujekwe $\mathrm{O}$, Patel R, Webb EA, Lawlor DA, Hargreaves JA. Measuring socio-economic position for epidemiological studies in low- and middle-income countries: a methods of measurement in epidemiology paper. Int J Epidemiol. 2012 doi:10.1093/ije/dys037:16. 
56. United Nations: World Urbanisation Prospects: the 2014 Revision. In. Edited by Department of Economic and Social Affairs PD. New York: Department of Economic and Social Affairs; 2014. https://esa.un.org/unpd/wup/CountryProfiles/.

57. Hu D, Hong X, Li X. Oral health in China - trends and challenges. Int J Oral Sci. 2011:3:7-12

58. Avlund K, Holm-Pedersen P, Schroll M. Functional ability and oral health among older people: a longitudinal study from age 75 to 80 . In: J Am Geriatr Soc. United States; 2001;49:954-62. doi: 10.1046/j.1532-5415.2001. 49187.x.

59. Henriksen BM, Axell T, Laake K. Geographic differences in tooth loss and denture-wearing among the elderly in Norway. Community Dent Oral Epidemiol. 2003;31(6):403-11.

60. Centers for Disease Control and Prevention (CDC) Morbidity and mortality weekly report. 2003;52(50):1226-9.

61. Islas-Granillo H, Borges-Yanez SA, Lucas-Rincon SE, Medina-Solis CE, CasanovaRosado AJ, Marquez-Corona ML, Maupome G. Edentulism risk indicators among Mexican elders 60-year-old and older. In: Arch Gerontol Geriatr, vol. 53. 53rd ed. Netherlands: 2010 Elsevier Ireland Ltd; 2011. p. 258-62.

62. Stewart Williams JA. Assessing the suitability of fractional polynomial methods in health services research. A perspective on the categorisation epidemic. J Health Serv Res Policy. 2011;16(3):147-52.

63. Pajukoski H, Meurman JH, Snellman-Grohn S, Sulkava R. Oral health in hospitalized and nonhospitalized community-dwelling elderly patients. In: Oral Surg Oral Med Oral Pathol Oral Radiol Endod. United States; 1999;88(4): 437-43. http://dx.doi.org/10.1016/S1079-2104(99)70058-2.

64. Haikola B, Oikarinen K, Soderholm AL, Remes-Lyly T, Sipila K. Prevalence of edentulousness and related factors among elderly Finns. J Oral Rehabil. 2008;35(11):827-35.

65. Inagaki K, Kurosu Y, Kamiya T, Kondo F, Yoshinari N, Noguchi T, Krall EA, Garcia RI. Low metacarpal bone density, tooth loss, and periodontal disease in Japanese women. J Dent Res. 2001;80(9):1818-22.

66. Mohammad AR, Hooper DA, Vermilyea SG, Mariotti A, Preshaw PM. An investigation of the relationship between systemic bone density and clinical periodontal status in post-menopausal Asian-American women. Int Dent J. 2003;53(3):121-5.

67. Brennan RM, Genco RJ, Hovey KM, Trevisan M, Wactawski-Wende J. Clinical attachment loss, systemic bone density, and subgingival calculus in postmenopausal women. J Periodontol. 2007;78(11):2104-11.

68. Shimazaki Y, Soh I, Koga T, Miyazaki H, Takehara T. Risk factors for tooth loss in the institutionalised elderly; a six-year cohort study. Community Dent Health. 2003;20(2):123-7.

69. Marcus PA, Joshi A, Jones JA, Morgano SM. Complete edentulism and denture use for elders in New England. J Prosthet Dent. 1996;76(3):260-6.

70. Spolsky W, Marcus M, Der-Martirosian C, Coulter ID, Maida CA. Oral health status and the epidemiologic paradox within Latino immigrant groups. BMC Oral Health. 2012;12:39.

71. Krall EA, Dawson-Hughes B, Garvey AJ, Garcia RI. Smoking, smoking cessation, and tooth loss. J Dent Res. 1997;76(10):1653-9.

72. Hanioka T, Ojima M, Tanaka K, Aoyama H: Association of total tooth loss with smoking, drinking alcohol and nutrition in elderly Japanese: analysis of national database. In: Gerodontology. 2007;24(2):87-92. doi: 10.1111/j.1741-2358.2007.00166.x.

73. Heegaard K, Avlund K, Holm-Pedersen P, Hvidtfeldt UA, Bardow A, Gronbaek M. Amount and type of alcohol consumption and missing teeth among community-dwelling older adults: findings from the Copenhagen Oral Health Senior study. J Public Health Dent. 2011;71(4):318-26.

74. Marcenes W, Steele JG, Sheiham A, Walls AW. The relationship between dental status, food selection, nutrient intake, nutritional status, and body mass index in older people. In: Cad Saude Publica. Brazil; 2003;19(3):809-816.

75. Tsakos G, Herrick K, Sheiham A, Watt RG. Edentulism and fruit and vegetable intake in low-income adults. In: J Dent Res. United States; 2010;89(5):462-67. doi: 10.1177/0022034510363247.

76. Desvarieux M, Demmer RT, Rundek T, Boden-Albala B, Jacobs DR, Jr., Papapanou PN, Sacco RL. Relationship between periodontal disease, tooth loss, and carotid artery plaque: the Oral Infections and Vascular Disease Epidemiology Study (INVEST). In: Stroke. United States; 2003;34:2120-125. doi: 10.1161/01.STR.0000085086.50957.22.

77. Lowe G, Woodward M, Rumley A, Morrison C, Tunstall-Pedoe H, Stephen K. Total tooth loss and prevalent cardiovascular disease in men and women: possible roles of citrus fruit consumption, vitamin C, and inflammatory and thrombotic variables. In: J Clin Epidemiol. England; 2003;56(7): 694-700. doi: http://dx.doi.org/10.1016/S0895-4356(03)00086.

78. Preet R. Health professionals for global health: include dental personnel upfront! In: Glob Health Action. Sweden; 2013;6:21398. http://dx.doi.org/10. 3402/gha.v6i0.21398.

\section{Submit your next manuscript to BioMed Central and we will help you at every step:}

- We accept pre-submission inquiries

- Our selector tool helps you to find the most relevant journal

- We provide round the clock customer support

- Convenient online submission

- Thorough peer review

- Inclusion in PubMed and all major indexing services

- Maximum visibility for your research

Submit your manuscript at www.biomedcentral.com/submit
Biomed Central 